\title{
Anaesthetic Management of a Parturient with Becker's Myotonia Congenita using propofol, rocuronium and sugammadex Case report
}

\author{
Kosinova M. ${ }^{1}$, Stourac P. ${ }^{2}$, Vohanka S. ${ }^{3}$, Huser M. ${ }^{4}$
}

${ }^{1}$ Department of Anaesthesiology and Intensive Care Medicine, University Hospital Brno, Medical Faculty of Masaryk University, Brno, Czech Republic ${ }^{2}$ Department of Paediatric Anaesthesiology and Intensive Care Medicine, University Hospital Brno, Faculty of Medicine, Masaryk University, Brno, Czech Republic

${ }^{3}$ Department of Neurology, Medical Faculty of Masaryk University, University Hospital Brno, Brno, Czech Republic ${ }^{4}$ Department of Obstetrics and Gynaecology, Medical Faculty of Masaryk University, University Hospital Brno, Czech Republic

Background: Becker's Disease is an autosomal recessive type of myotonia congenita. Worldwide prevalence is about $1 / 100000$. It is linked to mutations in CLCN1, the gene encoding skeletal muscle chloride channel. It reduces flow of chloride ions during repolarization and leads to sustained muscle contractions. Typical clinical symptoms are myotonic stiffness and "warm-up" phenomenon.

Case report: 27 year old primipara with homozygote recessive mutation in CLCN1 (c.1437_1450del,p.480HfsX24) was indicated to elective caesarean section in 40 gestational week. In personal history she had thoracic stabilisation for scoliosis and hypothyreosis. We decided to provide the general anaesthesia with propofol in TCI mode (Schnider mode, $\mathrm{C}_{\mathrm{e}}=\mathrm{effective} \mathrm{concentration} 5 \mathrm{mcg} / \mathrm{ml}$ ) and rocuronium $1 \mathrm{mg} / \mathrm{kg}$ IV for rapid sequence induction, monitoring the depth of neuromuscular blockade (NMB) on TOF WATCH SX device [figure 1,2]. The male newborn (APGAR score 9-10-10) with no signs of pathology in acid-base balance in arterial umbilical blood was delivered. At the end of surgery $\left(\mathrm{C}_{\mathrm{e}}=1 \mathrm{mcg} / \mathrm{ml}, \mathrm{TOF}=0, \mathrm{PTC}=0\right)$ we administered sugammadex $4 \mathrm{mg} / \mathrm{kg} \mathrm{IV}$. It takes $2 \mathrm{~min}$ and $15 \mathrm{sec}$ to reach TOF ratio $90 \%$ and subsequent extubation. After extubation she was breathing adequately, communicative, transferred to the recovery room and after two hours with no signs of residual NMB or respiratory problems back to the gynaecological ward to the monitored postoperative room. She was discharged home on 4th day [table 1].

Discussion: To the best of our knowledge, this is the first report of anaesthetic management of a parturient with Becker's myotonia congenita who underwent CS under general anaesthesia. In this case we wanted to aware of using malignant hyperthermia (MH) triggering drugs, though the association with $\mathrm{MH}$ has been regarded as highly unlikely, suxamethonium which can cause total body rigidity and subsequent difficult airway management and neostigmine which can cause myotonic response. Since there can be also increased sensitivity to non-depolarizing neuromuscular blocking agents we monitored the depth of NMB.

Table 1

Timing of all events during anaesthesia of a parturient with Becker's Myotonia Congenita

\begin{tabular}{|c|c|}
\hline Event description & $\begin{array}{c}\text { Time } \\
\text { (h:mm:ss) }\end{array}$ \\
\hline Preoxygenation with $100 \%$ oxygen & 0:00:00 \\
\hline Propofol TCI $-\mathrm{C}_{\mathrm{e}}=5 \mathrm{mcg} / \mathrm{ml}$ and stop after first bolus & 0:03:00 \\
\hline Rocuronium 1mg.kg-1 IV & 0:04:00 \\
\hline ST $10 \%$ on TOF Watch SX ${ }^{\circledR}$ & 0:04:32 \\
\hline Skin incision & 0:04:51 \\
\hline $\mathrm{EtCO}_{2}$ appearance $=$ orotracheal intubation & 0:05:05 \\
\hline TCI start with setting $\mathrm{C}_{\mathrm{e}}=3 \mathrm{mcg} / \mathrm{ml}$ & 0:07:23 \\
\hline Umbilical cord clamping + opioids+uterotonics + TCI setting: $\mathrm{C}_{\mathrm{e}}=5 \mathrm{mcg} / \mathrm{ml}$ & 0:08:08 \\
\hline TCI setting of $\mathrm{C}_{\mathrm{e}}=0.01 \mathrm{mcg} / \mathrm{ml}$ & 0:26:05 \\
\hline Last skin suture & 0:39:01 \\
\hline Decrease in calculated $\mathrm{C}_{\mathrm{e}}$ of propofol to $1 \mathrm{mcg} / \mathrm{ml}$ & 0:40:33 \\
\hline TOF $>90 \%$ on TOF Watch SX ${ }^{\circledR}$ & 0:42:48 \\
\hline Extubation & 0:43:02 \\
\hline
\end{tabular}

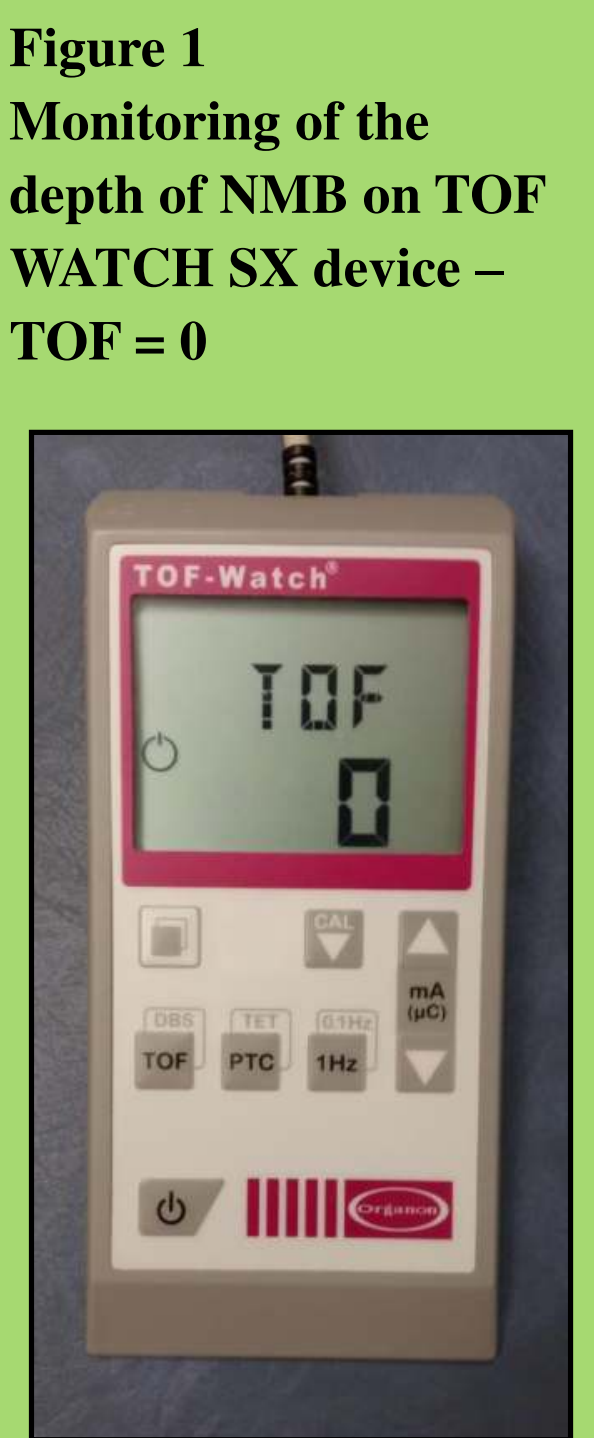

Figure 2

Monitoring of the depth of NMB on TOF WATCH SX device Measuring of PTC

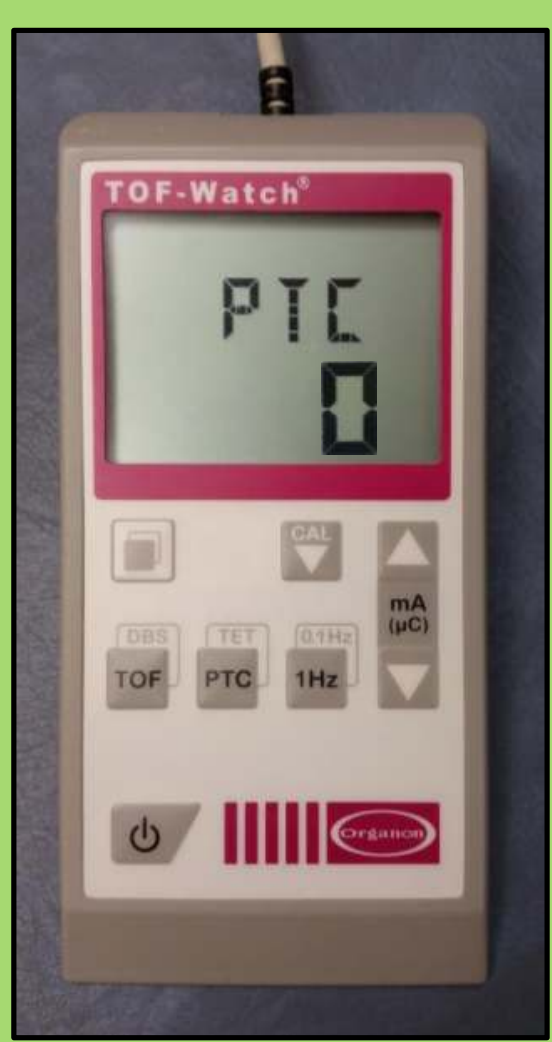

TCI = Target controlled infusion, $\mathrm{C}_{\mathrm{e}}=$ Effective concentration, $\mathrm{ST}=$ Single twitch,

$\mathrm{TOF}=$ Train of four, $\mathrm{EtCO}_{2}=$ End-tidal $\mathrm{CO}_{2}$

\section{Acknowledgement:}

Financial support: Czech Ministry of Health: Internal Grant Agency (ID: NT 13906-4/2012).

ClinicalTrials.gov ID: NCT01718236

Patient gave written consent for the report to be published.
Learning points: This case shows the possibility of using propofol with rocuronium for caesarean section in a parturient with Becker's myotonia congenita with the use of sugammadex for safe and rapid reversal of NMB. This enables standard maternal care for newborns to high risk parturients.

Kosinova M, Stourac P, Harazim H, Janku P, Huser M, Vohanka S. Anaesthesia for orphan disease: Rocuronium and sugammadex in the anaesthetic management of a parturient with Becker's myotonia congenita. Eur J Anaesthesiol. 2016 Mar 2. [Epub ahead of print] 